\title{
O trabalho docente na escola pública e o pensamento educacional de Antonio Gramsci
}

Luiz Aparecido Alves de Souza

Mestre em Educação pela Universidade Tuiuti do Paraná

\section{Resumo}

Esse estudo traz como inquietação saber o discurso do professor sobre sua condição de trabalhador na escola pública atual. Esforçamos por tecer reflexões a partir das contribuições de Gramsci em sua teoria sobre a Educação e o papel do Estado. Os professores têm nos reveladas três categorias centrais, a saber: 1) a sobrecarga de trabalho que lhe são atribuídas; 2) os baixos salários e 3) a falta de reconhecimento social da profissão. Importa afirmar que as aproximações do pensamento gramsciano sobre a educação apontam pistas para delinearmos possíveis horizontes de resistência e de construção de uma nova consciência de classe.

Palavras-chave: Gramsci; Trabalho Docente; Escola.

\begin{abstract}
This study brings anxiety to know how the discourse of the teacher about their status as workers in public school today. Strive to make reflections on the contributions of Gramsci in his theory on education and the role of the state. Teachers have revealed the three core categories, namely: 1) the workload assigned to it, 2) low wages and 3) the lack of social recognition of the profession. It said that the approaches of Gramscian thinking about education point out possible avenues for horizons of resistance and construction of a new classconsciousness.
\end{abstract}

Keywords: Gramsci; Teaching Work; School. 


\section{Introdução}

$\mathrm{N}$

as últimas décadas o problema referente às condições de trabalho e às práticas pedagógicas vem se destacando na literatura educacional brasileira bem como as pesquisas que têm denunciado as precárias e frágeis situações do docente que trabalha na escola pública.

Sabemos que a escola pública brasileira tem apresentado pouco entusiasmo com relação a uma instituição que ofereça propícias e adequadas condições para que desenvolva o trabalho docente, ao contrário: os salários são aviltantes, carreiras sem razoáveis possibilidades de ascensão, falta de condições básicas para o exercício da profissão desde estrutura física a apoio pedagógico, reconhecimento social muito baixo em relação ao alto nível de responsabilidade, burocratização excessiva.

A classe dos professores que atuam na rede pública de ensino tem percebido atualmente ( e isto não deixa de ser uma percepção histórica também) um distanciamento muito grande entre o discurso que enaltece o valor da educação na construção de uma sociedade melhor e a desvalorização no interior das práticas, “ quer através do tratamento precário que o Estado lhe reserva, vide os salários dos professores, quer porque através da crise de emprego e das modificações do trabalho o diploma deixou de ser um salvo-conduto para uma vida melhor". (CODO, 1999, p.294)

Procuramos ouvir 14 professores que atuam na rede pública de ensino entre os anos de 2007 e 2008 recorrendo à utilização das técnicas de observação direta e indireta e entrevistas semiestruturadas. São professores que atuam nas modalidades de ensino fundamental e médio em início e término de carreira.

Para nos auxiliar a discutir essa problemática, procuramos aproximar das contribuições de Antonio Gramsci, pensador italiano da primeira metade do século XX, que conviveu com uma Itália fascista, de ordem política e econômica dominada por uma burguesia liberal, que instigava a 
continuidade de uma sociedade proletarizada nas condições de trabalho e de uma escola pública italiana que contribuía para esse continuísmo.

Interessa para esse estudo provocarmos: Que educação é possível numa perspectiva gramsciana? Que atribuição à escola pública pensada por Gramsci aproxima das atribuições da escola pensada pelos gestores brasileiros? Há possibilidades de revertemos às condições precárias dos trabalhadores em educação no Brasil em uma releitura de Gramsci?

\section{Aproximações teóricas de trabalho, escola e educação em Gramsci}

A educação no sentido gramsciana está relacionada ao conceito de cultura, entendida como a forma de organização política, econômica e social de um determinado povo. A cultura, para o filósofo, é a síntese do ideário de uma sociedade e dessa maneira, expressa a concepção de povo e de organização e, portanto, toda forma de prática social e entre essas práticas o trabalho.

Partindo da consideração de que é pelo trabalho que uma sociedade estabelece toda a estrutura relacional de força e de poder, análise marxista recentes tem considerado que na instituição escola é que se desenvolve todo o processo de reprodução e que esta, se reveste de sua forma mais organizada.

Nas relações de trabalho as relações de forças expandem suas orientações, determinando ou não uma nova ordem comportamental que venha a ser desenvolvida pelos trabalhadores: seja esse comportamento ativo ou passivo, dependendo das condições políticas e culturais que os trabalhadores carregam consigo.

As condições de trabalho dos operários das fábricas italianas do século XX, muito pouco diferem das condições impostas pela sociedade neoliberal na atualidade, que acabam exigindo do trabalhador $o$ conhecimento técnico-operacional, tal como eram exigidas pelas elites burguesa liberal da Itália da década de 20. A educação humanística era reservada aos filhos da elite liberal, oportunizando a esse segmento social, 
habilidades intelectuais de darem continuidade ao processo de condução da política e da economia de seu país, ou seja, continuísmo histórico.

Gramsci defende uma escola unitária quanto à sua organização e a seus princípios formativos

Trata-se de uma escola única inicial de cultura geral, humanística, formativa, que equilibre e qualifique o desenvolvimento da capacidade de trabalhar manualmente (tecnicamente, industrialmente) e o desenvolvimento das capacidades de trabalho intelectual (Gramsci, 1978b. p.118).

Uma educação emancipatória que atende ao princípio filosófico de realizar a igualdade entre os homens, preocupando-se com a formação teórico-crítica e prática do cidadão: formar o trabalhador dinâmico, sabedor do contexto que vive, preocupado com a cultura, política e com a sociedade de seu tempo.

Assim, quando se pensa no panorama da educação brasileira na atualidade, percebemos pouco entusiasmo quanto à qualidade de uma educação que contribua para a formação de cidadãos, e que estes conquistem espaço no seio societário como articuladores de transformação na execução de um trabalho realizador.

O cenário nebuloso das estatísticas que o INEP (2003) tem apontado no que se refere à formação do professor, ao mercado de trabalho, à escolaridade do professor, aos indicadores de remuneração, ao gênero da formação continuada e às condições materiais de trabalho, a partir do discurso e da prática, inviabilizem a constituição de uma classe de docentes intelectuais que possam promover no espaço efetivo de seu trabalho - a escola, possibilidades de uma transformação emancipatória.

Dados estatísticos do INEP a partir da década de 1980 do século passado indicam quanto à jornada de trabalho, que $25 \%$ dos docentes estão submetidos a uma margem superior de 40 horas semanais. Esta situação demonstra duas razões, a saber: 1) a falta de professores faz com que eles atuem em mais de um turno ou mesmo em mais de uma escola e, principalmente, 2) a necessidade de aumentar os rendimentos, o que torna inviável, pois concorrem com outras atividades que exigem tempo adicional 
para a docência: planejamento das atividades em sala de aula, disponibilidade para oferecer atendimento ao aluno e atividade administrativa relacionadas à escola.

Um outro agravante circunscreve no abandono ou no absentismo do docente do seu espaço de trabalho (ZARAGOZA, 1999, p.61), considerando-se as pressões que sentem no trato com os discentes, junto aos mecanismos oficiais que destituem a autonomia de seu trabalho, o que leva o professor à desistência de sua profissão.

Codo (1999) explicita esta situação considerando a ocorrência na educação norte- americana, de acordo com dados estatísticos de professores que, após dez anos de efetivo trabalho, estão pedindo licenças, ou remanejamento para outras funções, migrando para trabalhos técnicoadministrativos. Em seu texto "[...] um trabalho, na prática, desvalorizado, mas importante o suficiente para que se culpe o professor por todas as mazelas da sociedade" (p.299)

Muitos desses fatores são frutos de uma reconfiguração do mundo do trabalho, que não foi realizada a contento no que diz respeito a suprir as necessidades do professor, na mesma escala em que este é cobrado.

Em Gramsci, condições como estas são refletidas em suas obras, a saber, quando discute as categorias cultura e revolução atribui qual seria o papel dos intelectuais na esfera da educação italiana: intelectuais tradicionais ou orgânicos? O filósofo recomenda que o papel dos intelectuais orgânicos seriam o de propor uma nova conjuntura de ações, que trouxessem a libertação da sociedade do cárcere da alienação política, que por sua vez são resultados da debilitada escola fragmentada em educação com oferta para os filhos da burguesia e outra para os filhos dos operários.

Gramsci considera a necessidade e importância do papel dos intelectuais orgânicos no centro de difusão de idéias e da formação de opiniões no cotidiano dos trabalhadores, pois para o filósofo a questão da cultura agora está relacionada à noção de hegemonia: 
Se burgueses e latifúndios dominam o cenário político isso se deve, em grande parte, à ação dos intelectuais na formação de uma concepção de mundo, no trabalho quotidiano de difundir idéias e formar opiniões, principalmente nos meios de comunicação. Para a classe operária, conquistar a direção política a partir de um conjunto de alianças de classes significativa, também, conquistar a direção cultural, o que implicava elaborar a sua própria concepção de mundo, isto é, um modo de pensar independente, que expressasse as contradições vividas no quotidiano (SCHLESENER, 2002, p. 192).

Formar uma contra-hegemonia no interior da classe dos trabalhadores em educação seria um dos avanços necessários a colaborar na resistência da hegemonia burguesa afinada e afirmada no cotidiano social e escolar do capitalismo.

Antunes (1999) afirma que o processo de entendimento de trabalho só pode ser compreendido uma base de estrutura social, na qual os sujeitos aplicam sua ideação, resultante de sua consciência. Para ele, o fato de buscar a produção e a reprodução da sua vida societal por meio do trabalho e da luta por sua existência, o ser social cria e renova as próprias condições da sua produção. (p.136). Com isso, o trabalho passa a ser o resultado de um sujeito que atribui significado ao mundo material, que se encontra diante do seu processo consciente.

Podemos recorrer a Gramsci (1978) quando diz que o homem é como uma síntese das relações sociais que ele estabelece na produção de sua existência (p.38-44). Situamos aqui que o homem é produzido historicamente, como resultado das apropriações que ele faz do espaço produtivo e do tempo que dispõe para tanto. Isto indica que o conceito de trabalho vai permitindo discorrer na proporção das relações humanas que preenchem este espaço.

Para o âmbito da educação, devemos refletir sobre o desenvolvimento das relações sociais e políticas que se estabelecem no ambiente da escola pelos sujeitos que nela transitam. Especificamente o professor, na condição de trabalhador, busca estabelecer mediações com o saber, produto de seu trabalho, com a técnica, esta elaborada nas relações mútuas dos produtores dos saberes, elementariza-se, também, "a 
apropriação dos bens produzidos, as idéias, as instituições, ideologias que buscam legitimar o modo de os homens se relacionarem na produção de sua existência”. (FRIGOTTO, 1993, p.74)

\section{A condição dos trabalhadores docentes na escola pública e as perspectivas de transformação frente ao pensamento de Gramsci}

Nossa pesquisa indagou os professores sobre o que eles mais sentem que interferem no trabalho docente, e sobre o que gera desconforto. Os respondentes, na totalidade dos professores, relataram, generosamente, o que os desconforta.

Dos 14 professores entrevistados e observados, 10 professores concordaram que a exaustiva carga de trabalho a que estão expostos cotidianamente os faz cair no desânimo e comprometem a qualidade das aulas, das relações profissionais interpessoais, de vida e até mesmo no relacionamento familiar.

A carga horária de trabalho deve oportunizar uma relação de qualidade da produção do produto, conforme alerta Vasquez (1977), mas corre o perigo de que se houver uma pauperização material e intelectual do operário, resulta do não reconhecimento do operário em relação ao seu próprio produto.

No que tange à educação, a sobrecarga de trabalho à qual o professor está sujeito impossibilita o reconhecimento dos resultados expostos ao término do seu desenvolvimento: o professor não consegue ou sente muita dificuldade em detectar deficiências e avanços na produção escolar de seus alunos; o professor tem dificuldades de detectar deficiências e avanços em sua própria prática laboral.

Gramsci considera a escola como o principal espaço agenciador de uma sociedade civil, fomentador da formação de intelectuais. Observamos uma preocupação essencial do filósofo em discutir e alertar sobre a composição de uma hegemonia civil, educando e formando o povo para o 
despertar crítico em ler a história que está sendo produzida no presente de uma determinada sociedade.

Por intelectuais devem-se entender não somente essas
camadas sociais tradicionalmente chamadas de
intelectuais, mas em geral toda a massa social que exerce
funções de organização em sentido amplo: seja no plano
da produção, da cultura ou da administração pública
(Gramsci, 2000. vol.3, p.201. caderno 3).

Como discutir a formação de novos intelectuais diante das atuais condições de formação e trabalho dos docentes que atuam na escola pública brasileira, considerando o processo de precarização que vem assumindo suas políticas?

A própria historicidade do sistema capitalista em suas relações de produção tem como essência a interferência nas relações sociais, considerando-se os mecanismos de autovalorização do capital, o que possibilita inúmeras e rápidas mudanças em suas formas de organização da produção e do trabalho, levando os trabalhadores a uma espoliação e proletarização de suas atividades.

É o que encontramos no campo educacional brasileiro, em que os trabalhadores são compelidos a intensificar individualmente suas forças intelectuais e físicas para abastecer um sistema que oprime, a partir de uma intensificação de suas forças produtivas que estão na sociedade, o que torna a força do trabalho individual enfraquecida e desarticulada diante das forças sociais. O professorado encontra-se anestesiado diante das demandas políticas, que decidem, por meio de leis e decretos, as condições de trabalho de cada sujeito operante no sistema educacional.

Alguns professores anunciaram em seus discursos essa questão: “Trabalho 40 horas/aulas, 32 diretamente com o aluno e 8 horas/atividade em que estou fora da sala de aula. É claro que essas 8 horas/atividades não são suficientes para a demanda de trabalho que tenho que dar conta [...]. E mesmo assim, quando falta um colega, a direção solicita, impõe mesmo, que eu utilize as minhas horas/atividades para cobrir a falta de um colega [...] É tamanha falta de sensibilidade!" (Entrevistado 3) 
Conforme podemos reconhecer no texto de Antunes (1999), os professores se situam na "classe que vive do trabalho" e no setor "improdutivo", ou seja, aqueles que se enquadram no setor de oferta de serviços e que, portanto,

Não se constituem como elemento diretamente produtivo, como elemento vivo do processo de valorização do capital e de criação de mais-valia. São aqueles em que, segundo Marx, o trabalho é consumido como valor d uso e não como trabalho que cria valor de troca (p.102).

O que ocorre é que, na atualidade a gestão pública tem entendido o quanto se torna mais visível e imediato investimento no pólo de construção de prédios escolares e equipamentos tecnológicos (isto quanto ocorre), do que propriamente investir na formação dos docentes e em uma política séria de Planos e Carreira para o Magistério, dado que isto não gera um impacto imediato e não projeta visibilidade (MÉSZÁROS, 2005, p.25).

Na fala de Mészáros apud Antunes (1995) encontramos esta idéia de que o setor improdutivo onde está alocado o trabalhador docente se, constitui em

[...] agentes não-produtivos, geradores de antivalor no processo de trabalho capitalista, mas que vivenciam as mesmas premissas e se erigem sobre os mesmos fundamentos materiais. Eles pertencem àqueles falsos custos e despesas inúteis, os quais são, entretanto, absolutamente vitais para a sobrevivência do sistema (102).

Sob a ótica do capitalismo, observamos que a produção efetivada pelos docentes é determinada pelo âmbito do trabalho em que o valor não é observável a curto e prazo e isto, para uma cultura que abraça o modelo econômico capitalista, implica numa categoria de segundo plano.

Outra questão que desconforta os docentes aparelhados à sobrecarga de trabalho é a questão salarial. Dos 14 professores, 10 apontaram que o salário conta muito no desempenho profissional. Afirmam que "o salário nos obriga a assumir um número grande de aulas o que acaba dificultando a preparação das aulas e sua qualidade” (Entrevistado 5) e que "o salário é decadente e nós ganhamos pouco por aquilo que fazemos e temos de dar 
conta de muita coisa [...] o salário interfere sim na prática docente, porque a partir do momento em que se é bem remunerado, o prazer que se tem no trabalho que exerço é bem maior, com certeza". (Entrevistado 1).

O professor é considerado pertencente à classe que vive do trabalho, pois segundo Antunes (1991) são todos

[...] aqueles e aquelas que vendem sua força de trabalho em troca de salário, incorporando, além do proletariado industrial dos assalariados do setor de serviços, também os proletariados rurais, que vende sua força de trabalho para o capital. Essa noção incorpora o proletariado precarizado, o subproletariado moderno [...] os trabalhadores assalariados da chamada "economia informal", que muitas vezes são indiretamente subordinados ao capital [...] (p.103).

O trabalho, portanto, no espaço da educação entende-se, na forma como está exposto, um cenário de precarização dadas às circunstâncias em que se encontra atreladas à imposição da economia capitalista que demonstra toda uma vontade de submeter os trabalhadores ao jugo do salário, que por sua vez se caracteriza de forma brutal e injusta, fomentando uma continuidade desta precarização.

Os professores, em sua totalidade, consideram que a profissão docente encontra-se desvalorizada há muito tempo e, sobretudo, questionam o momento histórico que estamos atravessando. Há cobranças e exigências de todos os setores da sociedade brasileira, requisitando melhor qualidade de ensino, com inúmeros argumentos que posicionam desde o crescimento do país à qualidade de vida dependente da educação recebida nos bancos escolares.

Percebemos certa contradição: professores desvalorizados socialmente e, por outro lado, sociedade exigindo, mesmo que seja somente pelo discurso, educação com qualidade. Alguma está errada!

Mészáros (2005) afirma que a falta de uma política afirmativa na valorização da educação pública encontra-se na esfera da visibilidade. O que dá mais visibilidade: investimentos em construções de edifícios, equipamentos funcionais para os estabelecimentos escolares, reformas de escolas, etc (mesmo que nenhuns desses elementos citados são atendidos 
devidamente), ou investimentos em formação acadêmica séria, aprofundada, salários, plano de cargos e carreira? O que promove maior impacto social e, portanto, projeção política na sociedade?

Em Gramsci encontramos possibilidades de articular-se movimento de resistência e de transformação da ordem e condições impostas pela conjuntura capitalista de produção da materialidade humana: "formar uma força de resistência moral e uma profundidade de sentimentos que são a base de um empreendimento revolucionário" (SCHLESENER, 2002, p.182), despertar para um espírito combativo e, neste sentido, os docentes precisam experimentar o sentimento e a pertença de classe trabalhista, procurando estabelecer diálogos e aproximações com os sindicatos, grupos de estudos e reflexões sobre as condições de formação de exercício da profissão, socializar experiências, leituras e posicionar suas apropriações do presente produzido pela suas práticas.

Um dos professores entrevistados explicita essa questão quando afirma que "o que mais me angustia é que nós professores, que temos como função na sociedade despertar o senso crítico de nossos alunos, somos os primeiros que não possuímos essa crítica [...] quando ocorrem as manifestações de rua, aparece meia dúzia, o restante fica na escola trabalhando ou tiram o dia de folga." (Entrevistado 8).

A importância de modificar a consciência é uma das preocupações centrais de Gramsci que entende que, somente a partir dessa mudança é que pode mudar a hegemonia dominante e que essa mudança deve ocorrer no movimento da própria organização de uma contra-hegemonia e que deve ser produzida pela classe dos dominados.

Os professores entrevistados têm apontado três formas de ver a desvalorização social da profissão: a culpabilidade do próprio professorado, que tem demonstrado socialmente atitudes de conformismo e passivismo, o governo, que circunscreve o valor da categoria profissional somente nos discursos oficiais; a sociedade, na figura dos alunos e pais, que se distanciam da esfera governamental relegando as reivindicações no âmbito da escola e na esfera do professorado. 
A noção de revolução para Gramsci situa justamente na leitura lúcida, atuante, do contexto que produz e que intervém, seja por aqueles que estão na gestão e que pensam as políticas educacionais, e que muitas vezes pertencem à classe dos dominados e que definem um papel de continuidade e manutenção da ideologia burguesa, ou por aqueles que se encontram no labor de suas práticas.

É evidente que Gramsci, estimula aos que se encontram na condição de dominados, e, portanto, estamos nos referindo aos docentes que atuam no campo da prática, a transitarem pelos espaços que apresentam os debates, confrontos, ou seja, onde produz a intelectualidade, situação atual que se tem distanciado cada vez mais da escola, e o docente acaba restringindo o seu trabalho a um mero executor-reprodutor, operante e não um intelectualizador de novas possibilidades de ação.

\section{Conclusão}

Compreender a complexidade da categoria trabalho inserido no contexto da escola atual, diante da conjuntura das suas políticas formativas e trabalhistas exige rigor, centralidade e uma imensurável disposição acadêmica de revisitar os clássicos e os contemporâneos para apoderarmosnos da ousadia e da coragem intelectual.

Buscamos aproximarmos da categoria trabalho docente inserida no contexto da escola pública, com suas determinantes situacionais e operacionais mobilizadas pelas políticas educacionais, e o olhar educacional de Antonio Gramsci em apontar algumas pistas para possíveis avanços na discussão do protagonismo desejável que se espera do professor diante das rupturas e fragmentação pelo qual, sobretudo, a educação brasileira vêm atravessando.

Reconhecer que Gramsci nos alerta que o desenvolvimento da prática pedagógica na Escola, mantida pelo Estado muito pouco pode e quer promover o espaço da transformação, haja vista, que sua reprodução é de 
manutenção da ordem vigente e que sua intencionalidade é de promover a continuação do contexto atual.

A transformação para Gramsci pode vir a ocorrer no estabelecimento da hegemonia proletária, ou seja, na tomada de consciência dos professores de suas reais condições de trabalho, mas também na apropriação de sua função no processo de mudança, no contexto capitalista e ainda, de perceber que a escola é parte do aparelho de Estado.

Com a apropriação de uma nova consciência produtora de uma contra-hegemonia, Gramsci aponta que uma nova hegemonia instaura-se: a hegemonia do proletário. Essa hegemonia tem a função de cercar o “aparelho ideológico burguês com uma contra-ideologia, ao mesmo tempo emerge uma crise denominada como crise da hegemonia burguesa possibilitando o surgimento de espaços de resistência" (CARNOY, 1986, p.33).

Percebemos no decorrer deste estudo, problemáticas levantadas ao dar voz ao professor que possibilitaria a construção de outras categorias de pesquisa sobre o trabalho docente, a saber:

1) o professor como todo segmento profissional, ocupa o interior de um sistema ditado por uma ordem econômica capitalista que força a manutenção e reprodução das relações de forças e poder do Estado nas escolas;

2) as estruturas e o funcionamento do ensino são orquestrados pelos ditames desse mercado econômico/consumista e, portanto, a educação, bem como seus sujeitos sofrem os impactos do sistema. Assim, o quadro estrutural sobre o qual está organizado o sistema educacional repercute diretamente sobre os processos de produção e reprodução social, em particular de seus sujeitos;

3) desdobram-se os empobrecimentos individuais dos professores, materiais e intelectualmente, ao se comporem para a vida profissional e, diante desse contexto, os professores conseguem extrair atitudes de possíveis transformações isoladas em suas práticas 
e que em uma abordagem gramsciana necessitaria de um movimento coletivo ideológico;

4) os discursos dos professores oscilaram entre o ideal que trazem como possibilidade de ainda continuarem desenvolvendo sua profissão e o real, em que situam a crueza e o desconforto resultante de um processo externo das condições de trabalho que sofrem no cotidiano.

Em Gramsci, encontramos o desconforto de perceber que as condições de trabalho são impostas pelas esferas de poder, que intencionalmente, indicam a sociedade que desejam conceber e formar. Mas, percebemos que a intelecção dessa intencionalidade deve ser apropriada pelos intelectuais que transitam no interior da sociedade civil e que, preferencialmente, uma das classes desses intelectuais, seriam a dos professores que devem se inflamar pelo espírito combativo desenvolvido na coletividade da própria escola. Aí está o grande desafio da classe dos trabalhadores em educação no Brasil.

\section{Referências bibliográficas}

ANTUNES, R. Os sentidos do trabalho: ensaio sobre a afirmação e a negação do trabalho. São Paulo: Boitempo, 2000.

CARNOY, M. Educação, economia e estado: base e superestrutura, relações e mediações. São Paulo: Cortez: Autores Associados, 1986.

CODO, W. et alli. Educação: carinho e trabalho. RJ: Petrópolis: Vozes, 1999.

FRIGOTTO, G. (org.) Educação e crise do trabalho: perspectivas de final de século. RJ: Petrópolis: Vozes, 1998.

GRAMSCI, A. Os intelectuais e a organização da cultura. Rio de Janeiro: Civilização Brasileira, 1978.

GRAMSCI, A. Cadernos do Cárcere: Maquiavel, notas sobre o Estado e a política. Volume 3. Trad. COUTINHO, Carlos N. et alli. 1 ed. Rio de Janeiro: Civilização Brasileira, 2000.

MÉSZÁROS, I. A educação para além do capital. São Paulo: Boitempo, 2005.

NOSELLA, P. A escola de Gramsci. Porto Alegre: Artes Médicas, 1992. 
SCHLESENER, A. H. Revolução e cultura em Gramsci. Curitiba: Ed. UFPR, 2002.

VAZQUEZ, A. S. Filosofia da práxis. Rio de Janeiro: Paz e Terra, 1977.

ZARAGOZA, J. M. O mal-estar docente: a sala de aula e a saúde dos professores. Bauru, SP: EDUSC, 1999. 